\title{
COMPARISON BETWEEN TWO LIDAR METHODS TO RETRIEVE MICROPHYSICAL PROPERTIES OF LIQUID-WATER CLOUDS
}

\author{
Cristofer Jimenez ${ }^{1 *}$, Albert Ansmann${ }^{1}$, David Donovan ${ }^{3}$, Ronny Engelmann ${ }^{1}$, Jörg Schmidt ${ }^{2}$ and \\ Ulla Wandinger ${ }^{1}$
}

${ }^{1}$ Leibniz Institute for Tropospheric Research (TROPOS),Leipzig, Germany, *jimenez@tropos.de

${ }^{2}$ University of Leipzig, Institute for Meteorology (LIM), Leipzig, Germany

${ }^{3}$ Royal Netherlands Meteorological Institute (KNMI), De Bilt, The Netherlands

\begin{abstract}
Since 2010, the Raman dual-FOV lidar system permits the retrieval of microphysical properties of liquid-water clouds during nighttime. A new robust lidar depolarization approach was recently introduced, which permits the retrieval of these properties as well, with high temporal resolution and during daytime. To implement this approach, the lidar system was upgraded, by adding a three channel depolarization receiver. The first preliminary retrieval results and a comparison between both methods is presented.
\end{abstract}

\section{INTRODUCTION}

The research on aerosol-cloud interaction [1] has intensified during the last years. Large uncertainties in the aerosol impact on liquid-water cloud evolution exist. To characterize this influence, accurate and simultaneous observations of the microphysical properties of the clouds and of aerosols below the clouds base are needed. Many scientist have attempted to estimate the microphysical properties of liquid clouds by analyzing the multiple scattering effects with lidar $[2,3,4,5,6]$.

By measuring the nitrogen Raman signal returns with two FOVs, the retrieval of the single scattering extinction coefficient and the effective radius in thin layered liquid water clouds is possible $[4,5]$. Since 2010, measurements of the Raman dual FOV lidar at TROPOS were used for this purpose. By combining the cloud results with vertical wind measurements from a Doppler lidar, a statistical analysis of the aerosol-cloud-dynamics relationship based on lidar measurements was possible $[7,8]$. However, for a deep statistical analysis, much more measurements are required, and since the dual-FOV is limited to nighttime measurements, an alternative method to extend the measurements to the daytime is needed.

Recently a robust optimal estimation procedure to retrieve this microphysical properties from lidar depolarization measurements was developed [6]. This is an innovative application, carrying on with previous work with the dual FOV techniques developed in the same group. The method makes use of the relationship between cloud multiple scattering effect and light depolarization by cloud droplets [9].

In order to implement this method, three telescopes for high accuracy depolarization measurements were implemented in the multi-wavelength Tropospheric Raman lidar for Temperature, Humidity, and Aerosol profiling (MARTHA). For first time, two different lidar-based methods to study the microphysics of liquid-water clouds are integrated in one lidar system, making possible a preliminary comparison of both methods in terms of the retrieved cloud microphysical and optical properties.

\section{TWO LIDAR METHODS FOR CLOUD MICROPHYSICS OBSERVATIONS}

A measurement case performed with the upgraded lidar MARTHA is presented in the Figure 1. A very stable stratocumulus layer developed in a polluted air mass. The time period analyzed was from 19:56 to 20:18 UTC. During this time period the cloud base remained stable (condition needed from both techniques).

\subsection{Raman dual-FOV lidar method}

This method is based on the measurement of nitrogen Raman backscatter signals $(607 \mathrm{~nm})$ with

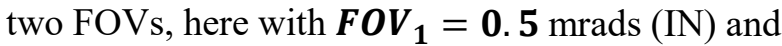
$\boldsymbol{F O V}_{\mathbf{2}}=2.0$ mrads (OUT). Due to the weakness of 
the Raman signals, both profiles where averaged over 22 minutes.

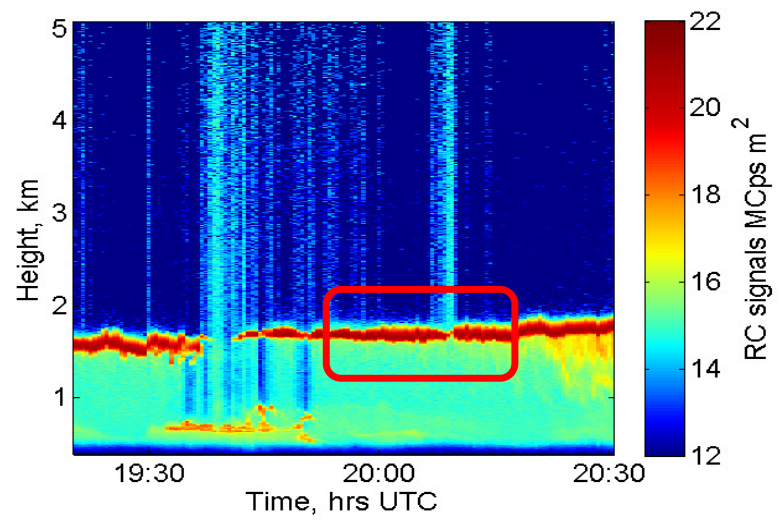

Figure 1: Height-time display of the range corrected elastic backscatter signal (532 $\mathrm{nm})$ measured on 8 November 2016. The red rectangle shows the selected time period (19:56 to 20:18 UTC).

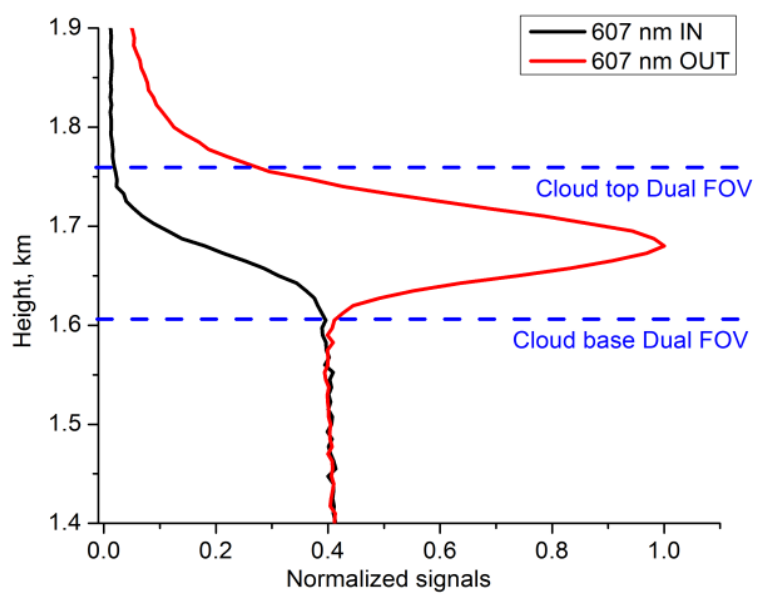

Figure 2: Normalized Raman signals from the two FOVs. Cloud base in $1.610 \mathrm{~km}$.

The cloud base is directly obtained from the $\mathrm{FOV}_{2}$ channel (red profile in Figure 2), since this channel only detects multiply scattered photons. In the Figure 2, the cloud base was set to $1.605 \mathrm{~km}$ and the cloud top to $1.76 \mathrm{~km}$, the cloud was then divided into homogeneous layers.

An analytical relationship between the Raman lidar returns and the cloud extinction coefficient and effective radius is used to simulate both Raman signals [10], and to identify the best matching pair of cloud extinction coefficient and effective radius profiles [5].
The result is shown in the Figure 3. From the extinction coefficient and the effective radius profiles the liquid water content (LWC), is determined, and finally the cloud droplet number concentration (CDNC) is estimated [7].

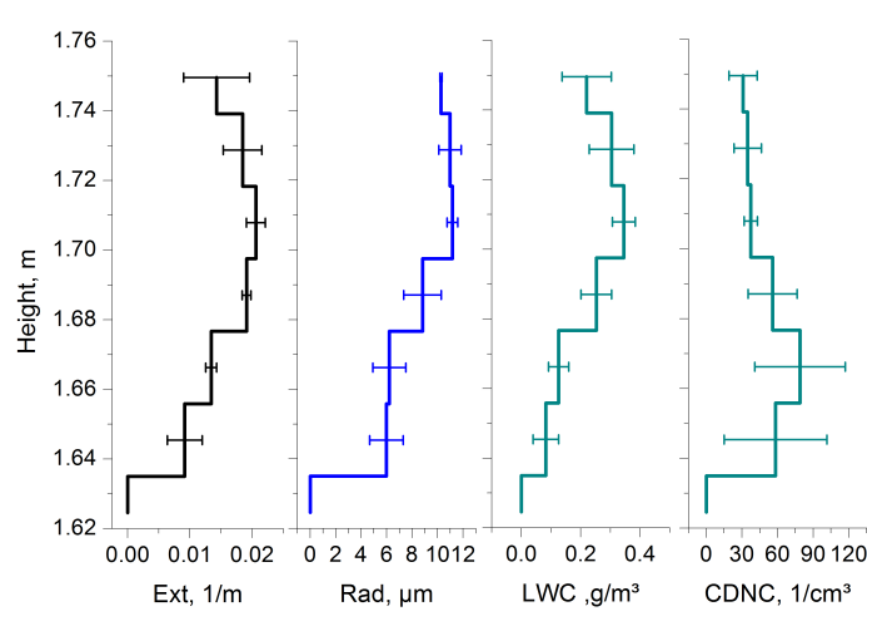

Figure 3: Results of the microphysical properties with the dual-FOV method.

\subsection{Depolarization method}

The same time period was selected to use the depolarization method [6], but the averaging is performed for 3-minute periods to obtain 7 profiles in total. The calibration for the polarization channels was based on a three signal procedure [11]. The found inter-channel calibration constant for this day is $\mathrm{Cr}=9.62$ and a cross-talk factor $\delta_{c}=0.04$.

The cloud base altitude for each profile considered in this inversion procedure is based on a threshold of $\beta_{I I}=0.05$, where $\beta_{I I}$ is the attenuated parallel signal. As an average value the cloud base were set to $1.62 \mathrm{~km}$. In this approach the cloud base region is considered as adiabatic, that means, a constant CDNC and a quasilinear LWC are assumed. At sub-adiabatic conditions $\alpha(z), R_{e f f}(z), \operatorname{LWC}(z)$ and $C D N C(z)$ are linked to each other [6].

A reference altitude of 100 meters above the cloud base was chosen. Look-up tables from the EarthCARE lidar Monte Carlo simulations were used for an optimal estimation minimization procedure. By means of the Look-up the attenuated calibrated parallel and cross polarized 
profiles can be computed as a function of cloud base altitude, FOV, $\alpha_{100}$ and $R_{e f f, 100}$.

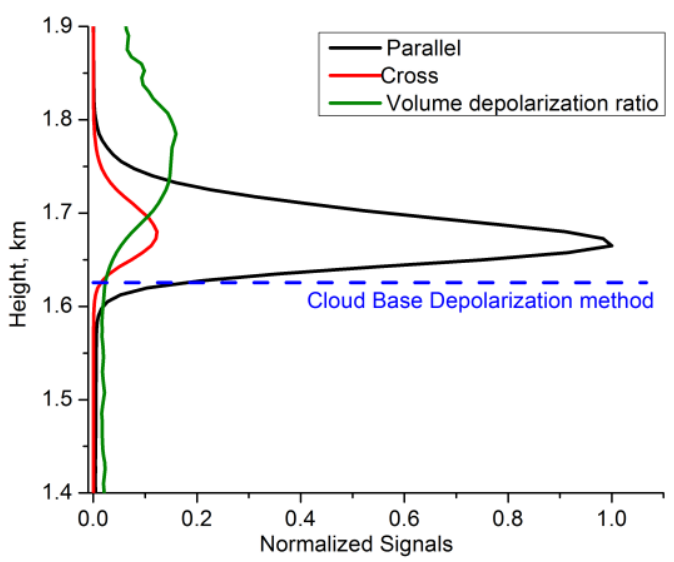

Figure 4: Averaged normalized polarization signals for the period from 19:56 to 20:18 UTC.

The inversion results of the depolarization method for 08 November 2016 from 19:56 to 20:18 UTC are shown in the Figure 5. On the bottom are the solutions for the extinction coefficient and the effective radius $100 \mathrm{~m}$ above the cloud base, as a second product the LWC and the CDNC for this reference height were obtained [6].

\section{COMPARISON BETWEEN BOTH METHODS}

From Figures 2 and 4, a very good agreement between both criteria to define the cloud base height was observed. According to the dual-FOV method the cloud base was $1.605 \mathrm{~km}$, the depolarization method detects the cloud base at $1.620 \mathrm{~km}$ height.

The dual FOV results (Figure 3) suggests that there is a quasi linear LWC and a constant CDNC as it has been assumed by the depolarization method, which makes this case a very good scenario for comparison.

Since the retrieval with the dual FOV method is given in one single profile for the 22-minute time period, for a first comparison the 7 retrievals obtained with the depolarization method are averaged. The values $100 \mathrm{~m}$ above the cloud base (at $1.72 \mathrm{~km}$ ) are presented in Table 1.

The depolarization method leads to higher values of the extinction coefficient and lower values for the effective radius. The large difference is then observed in the cloud droplet number concentration, which is about ten times higher when using the depolarization method.

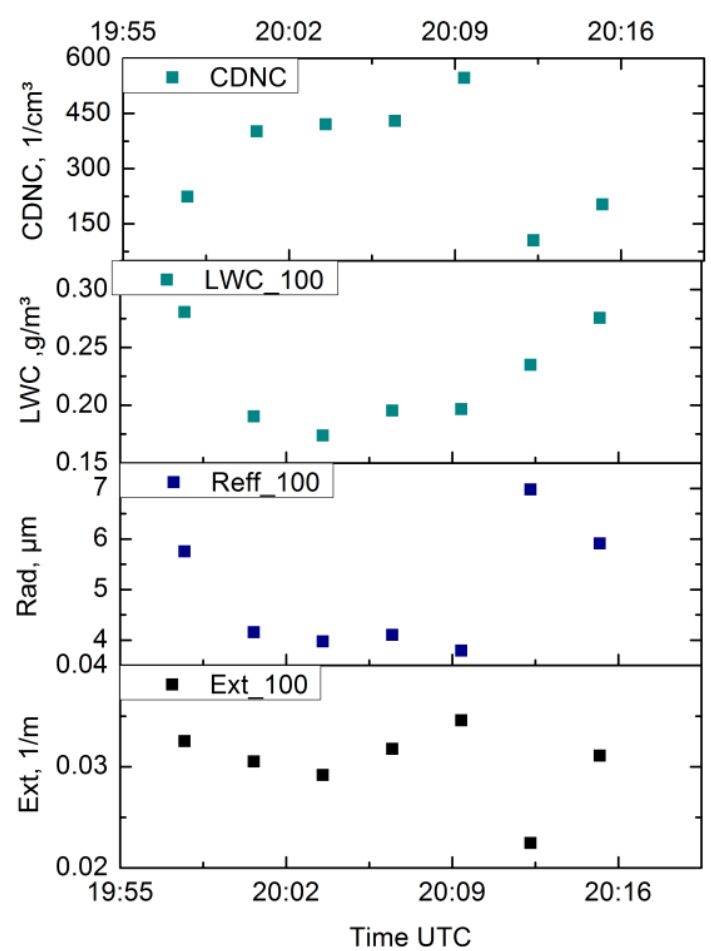

Figure 5: Inversion results from the depolarization measurements, by using the Donovan et al. method [6].

Table 1: Results $100 \mathrm{~m}$ above the cloud base.

\begin{tabular}{|c|c|c|}
\hline & Dual FOV & Depolarization \\
\hline$\alpha_{100}, \mathrm{~m}^{-1}$ & 0.01845 & 0.03029 \\
\hline$R_{\text {eff }, 100}, \mu m$ & 10.9768 & 4.9506 \\
\hline$L W C_{100}, \mathrm{gm}^{-3}$ & 0.3037 & 0.2209 \\
\hline CDNC $_{100}, \mathrm{~cm}^{-3}$ & 34.81 & 332.68 \\
\hline
\end{tabular}

\section{CONCLUSIONS}

A new depolarization-ratio method is implemented in the TROPOS MARTHA dual FOV Raman lidar to retrieve cloud microphysical properties as well as the cloud droplet extinction coefficient. First test measurements could be made. In the next phase, more cases need to be measured and analyzed in order to quantify the potential and accuracy of the new depolarization technique. These qualityassurance efforts are based on the comparison of 
the results obtained with the Raman dual-FOV lidar technique and the new depolarization technique.

\section{ACKNOWLEDGEMENTS}

The support of the lidar group of the Leibniz Institute for Tropospheric Research is acknowledged. The support of Dave Donovan of the KNMI is gratefully acknowledged. I acknowledge the financial support by DAAD.

\section{References}

[1] Twomey S., 1977: Influence of pollution on shortwave albedo of clouds, J. Atmos. Sci. 34, 1149-1152.

[2] Kim, D., Cheong, H., Kim, Y., Volkov, S., and Lee, J., 2010: Optical depth and multiple scattering depolarization in liquid clouds, Opt. Rev., 17, 507-512, doi:10.1007/s10043-010-0091-7.

[3] Roy G., Bissonnette L., Bastille C., and Valle' e G., 1999: Retrieval of droplet-size density distribution from multiple-field-ofview cross-polarized lidar signals: theory and experimental validation. Aplied Optics Vol. 38, No. 24

[4] Malinka, A. V. and Zege, E. P.,2007: Possibilities of warm cloud microstructure profiling with multiple-field-of-view Raman lidar, Appl. Optics, 46, 8419-8427.

[5] Schmidt, J., Wandinger, U., and Malinka, A, 2013: Dual-field-of-view Raman lidar measurements for the retrieval of cloud microphysical properties, Appl. Optics, 52, 2235-2247.

[6] Donovan D. P, H. Klein Baltink, J. S. Henzing, S. R. de Roode, and A. P. Siebesma, 2015: A depolarisation lidarbased method for the determination of liquid-cloud microphysical properties.

[7] Schmidt J., Ansmann A., Bühl J., Baars Wandinger U., Müller D, and Malinka A. V, 2013: Dual-FOV Raman and Doppler lidar studies of aerosol-cloud interactions: Simultaneous profiling of aerosols, warmcloud properties, and vertical wind, J. Geophys. Res. Atmos., 119, 5512-5527
[8] Schmidt J., Ansmann A., Bühl J, and Wandinger U., 2015: Strong aerosol-cloud interaction in altocumulus during updraft periods: lidar observations over central Europe.

[9] Hu, Y., Vaughan, M., Liu, Z., Lin, B., Yang, P., Flittner, D., Hunt, B., Kuehn, R., Huang, J., Wu, D., Rodier, S., Powell, K., Trepte, C., and Winker, D., 2007: The depolarization attenuated backscatter relation: CALIPSO lidar measurements vs. theory, Opt. Express, $15,5327-5332$.

[10]Malinka A. V., Zege E. P., 2003: Analytical modeling of Raman lidar return, including multiple scattering. Applied optics vol 42, Nro 6.

[11]Reichardt J, Baumgart R. and McGee T. J., 2003: Three-signal method for accurate measurements of depolarization ratio with lidar. Applied optics, col. 42, No 24. 